\title{
INDOOR AIR QUALITY IN DWELLING HOMES WITH MOLD PROBLEMS
}

\section{S. K. GIRI}

Associate Professor, Department Of Botany, S.M. Mohota College Of Science, NAGPUR-440 009 (M.S.) INDIA.

\section{Corresponding Email : drsk.giri@,rediffmail.com}

\section{ABSTRACT :}

The high prevalence of allergies in developed countries contributes to the increased public concern about indoor air quality. This has resulted in an increase in demand for environmental assessments, which at the present time are mainly focused on assessment of various indoor environments for evidence of air quality and fungal growth (mold). The fungal spores are identified using non-culturable or culturable analysis as a surrogate measure of exposure to fungal allergens. The present study was undertaken to sample the indoor air from different dwelling homes located in east and south regions of Nagpur city. Air sampling was done with Hi-Air sampler (Hi-Media - LA002) using Rose Bengal Agar strips (RBS-290, RBS-640). Simultaneously cello tape and cotton swabs were also used for direct microscopic examination of visible mould growth which is observed on the walls and other household materials like home furniture's, study tables, computer tables, wooden window frames, photo frames, AC filters) during rainy season i.e. June, 2012 to September, 2012. The concentrations of airborne fungal spores were found to be highest in indoor air than those of outdoor air (control). The fungal levels were found to be highest in the rainy season due to higher relative humidity and low temperature in dwelling homes. The most common airborne fungi, both indoors and outdoors (control air) were isolated are Aspergillus, Penicillium, Cladosporium, Curvularia, Alternaria, Trichoderma, Mucor, Rhizopus, Trichothecium, and nonsporulating fungi. This study mainly focused on Aspergillus and Penicillium species in the indoor and in control air of dwelling homes. Total 14 species of Aspergillus recorded in indoor air while in control it is recorded only six (06). Nine (09) species of Penicillium were recorded in indoor air and five (05) species recorded in control (outdoor air). Some of the surface fungi are also isolated from variety of household materials these are Alternaria spp., Aspergillus spp., Cladosporium spp., Curvularia spp., Mucor spp., Penicillium spp., Phoma spp., Rhizopus spp., Torula spp., and Trichoderma spp.

Keywords - Dwelling homes, airborne fungi, surface fungi, Aspergillus \& Penicillium spp. 


\section{INTRODUCTION:}

Buildings with a history of water damage are often associated with microbial contamination. It is well established that inhalation of fungal spores induces respiratory allergy symptoms in sensitized individuals; the most common symptoms include: Runny nose, stuffy nose, sneezing, nasal itching (rubbing), post nasal drip (throat clearing), itchy ears and throat. Nearly 20-30\% human populations are sensitized to fungal spores. These symptoms are clinically manifested as rhinitis, bronchial asthma and alveolitis [1,4,13]. Fungal spores involved in allergic diseases belong to 80 genera, the most significant of which belong to Ascomycetes, Basidiomycetes and Deuteromycetes (Anamorphic fungi) $[19,20]$. Recording and forecasting of fungal spore dispersion in indoor and outdoor environment attracts the interest of most scientists, aero biologists, general physician's and allergologists; since they form the basis of diagnosis and treatment of allergic diseases caused by fungi. To systematically evaluate the relationship between airborne fungi and adverse health effects, the fungal types and their relative frequencies in both indoor and outdoor air need to be known. Increased understanding of airborne fungal populations should enable better interpretation of fungal exposure found in building air quality investigations. Qualitative and quantitative assessments of fungi in indoor air are valuable. The literature on the occurrence of airborne fungi in the home and workplaces is extensive including some comprehensive reviews [4-6,820,25-34].

Dose-response relationships between exposures to fungi and symptoms are lacking. While a number of arbitrary numeric standards for "acceptable" levels of indoor fungi have been proposed [16], none of them are currently accepted by the scientific community. Although several studies conducted in different geographical locations around the world report "background" levels of fungal spores in buildings, these studies are limited in design and the majority of 
them do not specifically select buildings for the absence of fungal growth or moisture problems [13-16, 18-19, 26-28].

The evaluation of air sampling results is currently based on the comparison of the types and levels of fungal spores detected indoors versus those detected in matched outdoor samples. Indoor types of airborne spores should be similar to those detected outdoors and the levels should be lower. A critical consideration in the interpretation of air sampling results is the fact that indoor levels of airborne spores are always mixtures of spores from the following sources: infiltration of outdoor air, disturbance of dust reservoirs containing settled spores within a building, building occupants, and indoor fungal growth (both "minor and typical growth" and that occurring as a result of moisture problems) [24, 26]. Geographical location and climate are also responsible for particular construction practices, which partially account for the types and levels of indoor airborne fungal spores [21-23]. Therefore, it is reasonable to assume that background levels of indoor airborne fungal spores may vary according to location. Moisture is a limiting factor for fungal growth. Because of Nagpur is a subtropical location, seasonal climatic variations include abrupt changes in rainfall and ambient humidity levels among two seasons, the rainy season (from approximately (June-September) and the drier season (during the remaining months of the year). The objectives of this study was i) to describe the types and relative frequencies of both indoor and outdoor (control) airborne allergenic fungi, ii) to compare the species distributions of Aspergillus and Penicillium, iii) record the symptoms related to allergy or asthma on the basis of circulation of standard health related questionnaire, iv) find out surface fungi on various objects in residential buildings by cello tape and swab method, v) record meteorological data and compare total $\mathrm{CFU} / \mathrm{m} 3$ in indoor and outdoor (control) air of residential buildings during a rainy season in Nagpur, M.S.

\section{MATERIALS AND METHODS}

\section{SAMPLING AND ISOLATION METHODS}


Air was sampled by using a Hi-Media Air Sampler (LA-002) with Rose Bengal Agar strip (RB- PS640, PS-290). The sampling duration was 5 minutes and the samples were taken at fortnight intervals over a period of 4 months (June, 2012-September, 2012). Air samples were taken from east and south regions of Nagpur city during rainy season. Simultaneously cello tape and swab samples were also taken for direct microscopic examination of the presence of fungal spores and mycelium. A piece of transparent adhesive tape (Cello tape) is pressed gently on the surface and transferred to a microscope slide [2].

The questionnaire prepared for circulation to collect the information regarding health problem included the followings: Runny nose, stuffy nose, sneezing, nasal itching (rubbing), itchy ears and throat, post nasal drip (throat clearing), shortness of breath, wheezing, coughing, chest tightness, headache, skin itching, hypersensitivity pneumonities, respiratory allergy, allergic eyes (allergic conjunctivitis), redness under the lids and of the eye overall, watery, itchy eyes, swelling of the membranes. Building related problem includes: odor, water damage, and visual growth on various interior objects [http://www. medicinenet.com/allergy/article.htm].

\section{CFU COUNTS AND IDENTIFICATION}

Exposed strips were incubated in an inverted position at $27 \pm 2^{\circ} \mathrm{C}$; after four to five days of incubation, the colony forming units (CFUs) were visually counted and the total fungal count was expressed as colony forming units per cubic meter of air $\left(\mathrm{CFUs} / \mathrm{m}^{3}\right)$. The fungi detected per unit volume of air calculated as under:

$\mathrm{CFU} / \mathrm{m} 3$

Colonies on agar strip x 25

Sampling time in minutes (5)

The identification of isolated fungi was done after sub cultures were prepared from RBS's strips after seven to ten days. Isolated genera/species were identified by macroscopic and microscopic analysis with the help of standard 
published literature [35-38]. Fungi that failed to sporulate after 12 to 14 days were recorded as non-sporulating. Temperature, relative humidity and rainfall were measured by using thermometer and hygrometer device during the sampling period (Table 1).

\section{RESULTS AND DISCUSSION:}

Total 96 samples were collected from two different residential sites i.e. east and south; their average mean colony counts was calculated. The indoor environment of residential buildings showed highest colony counts (i.e. mean CFUs) than the outdoor (control) air, it was $2085 \mathrm{CFU} / \mathrm{m}^{3} \& 1746.25 \mathrm{CFU} / \mathrm{m}^{3}$ respectively. The present study revealed that total 37 fungal species belonging to 15 genera along with non-sporulating fungi were isolated in indoor air; while in outdoor (control) air recorded 37 species belongs to 28 genera excluding non-sporulating fungi (Table 3). The dominant fungi were isolated from indoor and outdoor (control) air of residences are shown in parentheses, Aspergillus (706.25 CFU/m³ /421.25 CFU/m³ C), Penicillium (360 CFU / m³ $/ 236.25 \mathrm{CFU} / \mathrm{m} 3$ (C), Cladosporium (175 $\mathrm{CFU} / \mathrm{m}^{3} / 176 \mathrm{CFU} / \mathrm{m}^{3}$ C), Curvularia (11.38 $\mathrm{CFU} / \mathrm{m}^{3}$ ), Mucor (196.25 CFU/m³/118.75 CFU/m³ @), Rhizopus (107.50 CFU/m³/143.75 $\mathrm{CFU} / \mathrm{m}^{3} \mathrm{C}$, Alternaria (102.50CFU/m³ $/ 176.25 \mathrm{CFU} / \mathrm{m}^{3}$ (), Trichoderma $(87.50$ $\mathrm{CFU} / \mathrm{m}^{3} / 50 \mathrm{CFU} / \mathrm{m}^{3} \mathrm{C}$, Fusarium spp. $\left(63.75 \mathrm{CFU} / \mathrm{m}^{3} / 36.25 \mathrm{CFU} / \mathrm{m}^{3} \mathrm{C}\right.$, Nonsporulating fungi $\left(96.25 \mathrm{CFU} / \mathrm{m}^{3} / 10 \mathrm{CFU} / \mathrm{m}^{3} \mathrm{C}\right.$, followed by other species which are recorded below $50 \mathrm{CFU} / \mathrm{m}^{3}$ (Table 3)

Total 10 dominant genera are isolated by direct cello tape and swab sampling method from various interior household materials and surfaces like wooden frames of windows, doors, photo frames, wooden furniture, sofa set, wooden racks, study table (space wood material laminated by papers), bathroom ceilings, kitchen sink, AC filters and wet wall surfaces; these are Alternaria spp., Aspergillus spp., Cladosporium spp., Curvularia spp., Mucor spp., Penicillium spp., Phoma spp., Rhizopus spp., Torula spp. and Trichoderma spp. (Table 2). The base level of indoor fungal spore counts may partly be caused by 
unnoticeable fungal micro-colonies that may develop on any temporarily wet surface $[15,21,22,24,26]$.

Though there is 37 species isolated in both the environments, but there is difference in genera recorded in outdoor (control) air might be due to external sources which favor the growth of different types of fungi. However, there may be other indoor fungal sources also; in residences accumulation of spores may occur as the airborne spores settle on various surfaces. These settled spores may be re-suspended in indoor air by air movements caused by human activities, such as cleaning or construction work or by changes in air humidity. Fungal spores may also be carried into the home by people's clothes $[13,15]$.

Aspergillus, Penicillium, Cladosporium, Curvularia, Alternaria, Trichoderma, Mucor, Rhizopus, Trichothecium is the dominant and frequently isolated genera/species recorded in present study. The majority of fungal genera were found both inside and outside the residential buildings, and several genera were more frequently found inside and the indoor exposures contained a greater number of species/genera than the outside exposures. This confirming the ubiquitous nature of these fungi, where the indoor environment capable of supporting spore survival in the absence of outdoor contributions to the indoor air $[1,9,12,13,18-19,24,26]$.

Tilak and Patil [3] studied the airspora of nine dwelling houses of Allergenic patients at Aurangabad by using Rotorod sampler. Cladosporium recorded the dominant spore type followed by Hyphal fragments, Curvularia, Aspergillus, Alternaria, Nigrospora and Insect scales. Santra and Chanda [8] investigated the indoor airspora of residential quarters at Calcutta. Spores of Aspergillus were predominant followed by Helminthosporium, Alternaria, Curvularia, Penicillium, Rhizopus, Cladosporium and Candida. They recorded that the seasonal periodicity of Aspergillus was maximum during the post monsoon period and minimum during the winter period. They recorded total 2,150 colonies in residential quarters. In the present investigation Aspergillus species 
also recorded maximum colony counts $\left(706.25 \mathrm{CFU} / \mathrm{m}^{3}\right.$ i.e. $\left.33.87 \%\right)$ in rainy season.

Nevalainen et al. [11] in Kuopio, Finland studied the fungal growth in buildings due to water damage which can cause irritation of respiratory mucosa, skin and eyes, as well as allergic diseases. It is also observed in present findings, visual fungal growth in buildings due to water damage or micro seepages, and other interior objects; which raise the indoor humidity up to $79 \%$ and that might be favors the fungal growth.

Most of the Phycomycetes members are predominant forms during the monsoon period with heavy rainfall, high humidity and low temperature. The extremely high concentration of this spore type is associated with the rainy months with high rains, temperature range between 20 to $36^{\circ} \mathrm{C}$ and the relative humidity of $85 \%$ or above [3]. Saprophytic microorganisms, by contrast are able to grow in environmental reservoirs and therefore readily contaminate interior substrates. Epicoccum and Penicillium have been shown to contain allergens [11,14], out of which Penicillium is frequently found in the indoor environments. Furnishings containing fabric that cannot be removed and washed (including upholstered furniture and installed carpeting) will become moldy in damp areas such as basements, kitchens and bathrooms [14-16]. Similarly, as the first few drops penetrate a leaky roof, previously dormant organisms begin growing in surface dirt on insulation or on structural wood. These materials develop surface contamination when they are continuously wet Kozak et al. [2].

Ramalingam [6] reported that Aspergillus, Penicillium and Cladosporium were abundant on wet wall surfaces. In the present study the samples of humid walls after critical examination indicate the presence of Cladosporium, Aspergillus, Penicillium, Chaetomium, Alternaria, Trichoderma and Mucor. This may be the source of microbial air pollution inside the residential buildings. 
Shivpuri et al., [4]; Singh, A.B. \& Singh, A.D. [23] reported Alternaria, Aspergillus, Chaetomium, Cladosporium, Curvularia, Drechslera, Epicoccum, Fusarium, Helminthosporium, Mucor, Rhizopus, Penicillium, Scopulariopsis and Trichoderma are associated with allergy and occupational risk factor among susceptible individuals. In the present findings all these genera were frequently isolated in indoor as well as in outdoor (control) air.

The nature of the landscape can affect levels of airborne spores immediately surrounding a building, especially one or two story residences and larger buildings with air intakes near the ground. Dense vegetation closely surrounding a home may increase the risk of microbial contamination within. Any construction defect that allows water entry through walls or roof or permits seepage of ground water will eventually cause microorganisms to flourish. Common construction practices that promote water damage include flat roofs (especially where flat and pitched roofs meet), complexes of buildings of differing heights (since water can intrude where buildings are joined) and residential basements in wet areas with improper drainage. Improperly sealed and ventilated on-grade concrete slab construction can be a problem when carpeting is installed directly on the continually damp surface as is often done in residences and many schools $[2,9,11-12,19,21-22,24-26]$. However, indoor situations, marked by high humidity in rainy season and, at least, traces of organic matter support the growth of fungi. Spores may come from many sources within buildings. They may come from fungi growing in vapor condensation on walls and paintwork and on food, or spores may accumulate in house dust and grow if the humidity is high enough $[11,15]$.

In the present investigation, total 14 species of Aspergillus were isolated and contributed total mean concentration $706.25 \mathrm{CFU} / \mathrm{m}^{3}$ in indoor air, while in outdoor (control) air it was recorded only 6 species and they contributed $421.25 \mathrm{CFU} / \mathrm{m}^{3}$. Aspergillus fumigatus is the most dominant species found in present study seems to be most frequent species causing allergic fungal 
sinusitis (AFS) and sinus aspergilloma [23]. Aspergillus flavus also reported the second most dominant species causing human infections. In addition, many $A$. flavus isolates produce aflatoxin B1, the most toxic and potent hepatocarcinogenic natural compound [22]. The second largest species was Penicillium isolated and recorded 9 species in indoor air while 5 species were recorded in outdoor (control) air. Total mean colony count of Penicillium was $360 \mathrm{CFU} / \mathrm{m}^{3}$ in indoor air whereas it was $236.25 \mathrm{CFU} / \mathrm{m}^{3}$ in outdoor (control) air. Species of Penicillium are reported to be allergenic and mycotoxigenic $[28,30-31]$.

The role of infections caused by the moulds likes Mucor and Rhizopus reported by Gniadek \& Macura [31]. In present investigation, Mucor spp. recorded 196 $\mathrm{CFU} / \mathrm{m}^{3}$ in indoor and $118.75 \mathrm{CFU} / \mathrm{m} 3$ in outdoor (control) air and Rhizopus contributed $107.50 \mathrm{CFU} / \mathrm{m}^{3}$ in indoor ambient air, while it is comparatively higher in outdoor (control) air which contributed $\left(143.75 \mathrm{CFU} / \mathrm{m}^{3}\right)$. It is reported that the indoor concentration of fungal taxa is higher than those of outdoors, which indicates the fungal sources inside the residential buildings. However, the presence of fungi in residential buildings does not necessarily imply a cause and effect relationship with respiratory allergy related symptoms, but that should be alert to individuals, general physicians and healthcare professionals to do more vigorous environmental testing. Penicillium, Aspergillus, and other related genera of fungi commonly amplify indoors when there are moisture problem. Therefore, particular attention is typically given to the levels of these fungal types detected indoors versus those detected outdoors, and, as previously suggested, the ratio of soil/phyloplane fungi should be considered a measure of fungal growth within buildings [19]. However, it should be noted that these fungi also commonly grow in house dust in buildings without obvious moisture problems and can be detected indoors at levels greater than those detected outdoors [27,28], as illustrated by the results of this study. This suggests that the contribution of infiltration of 
outdoor air to the levels of spores detected indoors was minimal. Therefore, the indoor/outdoor ratio for the Penicillium/Aspergillus group should be considered with caution in the interpretation of culturable/non-culturable airborne fungal reports, particularly when outdoor levels of these fungal types are low, as defined by outdoor aerobiology surveys [29]. Low levels of other genera or groups of fungi were also identified.

\begin{tabular}{|l|l|l|l|l|}
\hline \multicolumn{7}{|c|}{ Sampling dates, Relative humidity, Temperature, Rainfall, and Total mean } \\
CFU/m3.
\end{tabular}

\section{CONCLUSION:}

The indoor concentrations of fungi were found to be highest in rainy season as compare to outdoor (control) air. The indoor concentrations may reflect lower temperatures and high relative humidity's. No attempt has been made to find out the colony count comparison between two different study sites. The present 
study only concentrate on the prevalence and dominance of Aspergillus and Penicillium species isolated both from indoor and outdoor (control) environment of residences along with other fungal isolates.

The questionnaire prepared for circulation to collect the information regarding health problem included the followings: Runny nose, stuffy nose, sneezing, nasal itching (rubbing), itchy ears and throat, post nasal drip (throat clearing), shortness of breath, wheezing, coughing, chest tightness, headache, skin itching, hypersensitivity pneumonities, respiratory allergy, allergic eyes (allergic conjunctivitis), redness under the lids and of the eye overall, watery, itchy eyes, swelling of the membranes. Building related problem includes: odor, water damage, and visual growth on various interior objects.

There was a marked difference in the mean temperature and relative humidity's in Nagpur throughout the year. The amount of rainfall was noticeably high from June to September and the frequency of occurrence of mold spores was also recorded high in that period. In September, when there was maximum rainfall, we observed an appreciable change in the frequency or in the total number of genera of airborne and surface fungi.

This study reports general background levels of fungal species/genera in residential buildings with obvious moisture problems during a rainy season in Nagpur. This study also confirms the validity of general interpretative guidelines, but suggests that indoor/outdoor ratios of airborne fungal spores should be evaluated in conjunction with other factors, including ecological relevance of fungi, less lawn care, infrequent raking of leaves etc., all of which would increase the level of organic debris around the home. Some homes in our survey accounted for the high shade, high level of organic debris and uncared natural landscaping. This could imply an additive effect from each of these factors to raise the fungal concentration in indoor as well as in outdoor (control) air. 
Table 3.

Total fungi isolated from indoor and outdoor (control) environment, their total mean CFUs/m3 and percentage contribution

\begin{tabular}{|c|c|c|c|c|c|}
\hline S.No & Taxon & $\begin{array}{l}\text { Total } \\
\text { Mean } \\
\text { CFU/m3 } \\
\text { (Indoor) }\end{array}$ & $\%$ & $\begin{array}{l}\text { Total } \\
\text { Mean } \\
\text { CFU/m3 } \\
\text { Outdoor } \\
\text { (Control) }\end{array}$ & $\%$ \\
\hline 1 & Alternaria spp. & 102.5 & 4.92 & 176.25 & 10.09 \\
\hline 2 & Aspergillus candidus & 11.25 & 0.54 & 11.25 & 0.64 \\
\hline 3 & Aspergillus carbonarius & 16.25 & 0.78 & $\mathrm{NI}$ & - \\
\hline 4 & Aspergillus flavus & 197.5 & 9.47 & 117.5 & 6.73 \\
\hline 5 & Aspergillus fumigatus & 146.25 & 7.01 & 105 & 6.01 \\
\hline 6 & Aspergillus glaucus & 6.25 & 0.30 & NI & - \\
\hline 7 & Aspergillus nidulans & 12.5 & 0.60 & NI & - \\
\hline 8 & Aspergillus niger & 187.5 & 8.99 & 128.75 & 7.37 \\
\hline 9 & Aspergillus ochraceus & 17.5 & 0.84 & NI & - \\
\hline 10 & Aspergillus repens & 22.5 & 1.08 & NI & - \\
\hline 11 & Aspergillus sulphureus & 20 & 0.96 & $\mathrm{NI}$ & - \\
\hline 12 & Aspergillus sydowi & 11.25 & 0.54 & 25 & 1.43 \\
\hline 13 & Aspergillus tamarii & 15 & 0.72 & NI & - \\
\hline 14 & Aspergillus terreus & 15 & 0.72 & NI & - \\
\hline 15 & Aspergillus versicolor & 27.5 & 1.32 & 33.75 & 1.93 \\
\hline \multicolumn{2}{|c|}{$\begin{array}{l}\text { Total Mean CFUs \& \% of Asp. } \\
\text { Spp. }\end{array}$} & 706.25 & $\begin{array}{l}33 . \\
87\end{array}$ & 421.25 & 24.12 \\
\hline 16 & Aureobasidium sp. & $\mathrm{NI}$ & - & 12.5 & 0.72 \\
\hline 17 & Bipolaris spp. & NI & - & 26.25 & 1.50 \\
\hline 18 & Cladosporium spp. & 175 & 8.39 & 170 & 9.74 \\
\hline 19 & Chaetomella spp. & NI & - & 27.5 & 1.57 \\
\hline 20 & Chaetomium spp. & NI & - & 21.25 & 1.22 \\
\hline 21 & Cunninghamella sp. & NI & - & 5 & 0.29 \\
\hline 22 & Curvularia spp. & 113.75 & 5.46 & 166.25 & 9.52 \\
\hline 23 & Drechslera spp. & NI & - & 6.25 & 0.36 \\
\hline 24 & Epicoccum sp. & NI & - & 11.25 & 0.64 \\
\hline 25 & Fusarium spp. & 63.75 & 3.06 & 36.25 & 2.08 \\
\hline 26 & Geotricum spp. & NI & - & 3.75 & 0.21 \\
\hline 27 & Helminthosporium spp. & NI & - & 12.5 & 0.72 \\
\hline 28 & Monilia sp. & NI & - & 17.5 & 1.00 \\
\hline 29 & Mucor spp. & 196.25 & 9.41 & 118.75 & 6.80 \\
\hline 30 & Neurospora sp. & NI & - & 16.25 & 0.93 \\
\hline 31 & Oospora sp. & NI & $-\infty$ & 12.5 & 0.72 \\
\hline 32 & Penicillium chrysogenum & 63.75 & 3.06 & 98.75 & 5.65 \\
\hline 33 & Penicillium charlesii & 36.25 & 1.74 & 98.75 & 5.65 \\
\hline 34 & Penicillium citrinum & 53.75 & 2.58 & 43.75 & 2.51 \\
\hline 35 & Penicillium digitatum & 36.25 & 1.74 & $\mathrm{NI}$ & - \\
\hline 36 & Penicillium glabrum & 52.5 & 2.52 & NI & - \\
\hline
\end{tabular}


International Journal of Researches in

September 2013

ISSN No. (Online): Biosciences, Agriculture \& Technology

Issue-1, Volume-1

\begin{tabular}{|l|l|l|l|l|l|}
\hline 37 & Penicillium lutem & 45 & 2.16 & 17.5 & 1.00 \\
\hline 38 & Penicillium funiculosum & 8.75 & 0.42 & NI & - \\
\hline 39 & Penicillium nigricans & 6.25 & 0.30 & NI & - \\
\hline 40 & Penicillium notatum & 12.5 & 0.60 & NI & - \\
\hline 41 & Penicillium purpurrescens & 45 & 2.16 & 13.75 & 0.79 \\
\hline $\begin{array}{l}\text { Total Mean CFUs \& \% of Peni. } \\
\text { Spp. }\end{array}$ & $\mathbf{3 6 0}$ & $\mathbf{1 7 .}$ & $\mathbf{2 3 6 . 2 5}$ & $\mathbf{1 3 . 5 3}$ \\
\hline 42 & Phoma spp. & 12.5 & 0.60 & 6.25 & 0.36 \\
\hline 43 & Rhizopus spp. & 107.5 & 5.16 & 143.75 & 8.23 \\
\hline 44 & Sporobolomyces spp. & NI & - & 3.75 & 0.21 \\
\hline 45 & Scopulariopsis spp. & 7.5 & 0.36 & NI & - \\
\hline 46 & Sporotricum spp. & 7.5 & 0.36 & 7.5 & 0.43 \\
\hline 47 & Stemphyllum spp. & 8.75 & 0.42 & 3.75 & 0.21 \\
\hline 48 & Torula sp. & 22.5 & 1.08 & 12.5 & 0.72 \\
\hline 49 & Trichoderma sp. & 87.5 & 4.20 & 50 & 2.86 \\
\hline 50 & Trichothecium sp. & 17.5 & 0.84 & 12.5 & 0.72 \\
\hline 51 & Verticillium spp. & NI & - & 8.75 & 0.50 \\
\hline 52 & Non-sporulating fungi & 96.25 & 4.62 & 110 & 6.30 \\
\hline $\begin{array}{l}\text { Total Mean CFU/m3 \& \% } \\
\text { Contribution }\end{array}$ & $\mathbf{2 0 8 5}$ & $\mathbf{1 0 0}$ & $\mathbf{1 7 4 6}$ & $\mathbf{1 0 0}$ \\
\hline NI $=$ Not isolated & & & & \\
\hline
\end{tabular}

\section{REFERENCES:}

Gravesen, S., 1972. Identification of indoor airborne microfungi during 12 months from 44 Danish homes. Acta Allergol. 27: 327-354.

Kozak, P. P., J. Gallup, L. H. Cummins, and S. A. Gillman. 1979. Factors of importance in determining the prevalence of indoor molds.Ann.Allergy 43:88-94.

Tilak, S.T. and Patil, C.R. 1981. Air-spora of dwelling houses at Aurangabad. Proc. Nat. Conf. Envi. Bio. 215 -220.

Shivpuri, D.N. 1982. Studies in allergy to fungi in India. Asp. Allergy Appli. Immunol. 15:19-30.

Beaumont, F., H. F. Kauffman, H. J. Sluiter, and K. de Vries. 1984. A volumetric-aerobiologic study of seasonal fungus prevalence inside and outside dwellings of asthmatic patients living in northeast Netherlands. Ann. Allergy 53:486-492.

Ramalingam, A., 1988. Air Borne Aspergillus - in some intramural environments from mouldy walls. Ind. J. Aerobiol Vol. 1. No. 2, pp. 98. 
Hunter, C.A., C. Grant, B. Flannigan, and A.F. Bravery, 1988. Mould in buildings: The air spora of domestic dwellings. Int. Biodet. 24:81-101

Santra, S.C. and Chanda, S., 1989. Airborne fungal flora in indoor environments of Calcutta metropolis, India. Grana. 28:141-145.

Burge, H.A., 1990. Bioaerosols: Prevalence and health effects in the indoor environment. J. Allergy Clin. Immunol. Vol.86, No.5: 687-701.

Lacey, J., 1991. Aerobiology and Health: The Role of Airborne Fungal Spores in Respiratory Disease. In: D.L. Hawks worth Ed., Frontiers in Mycology. C.A.B. International, Kew, UK. pp. 157-185.

Nevalainen, A., Pasanen, A.L., Niininen, M., Reponen, T., Kalliokoski, P. and Jantunen, M.J., 1991. The indoor air quality in finish homes with mold problems. Envir. Int. 17:299-302.

Verhoeff, A. P., J. H. van Wijnen, B. Brunekreef, P. Fischer, E. van ReenenHoekstra, and R. A. Samson. 1992. Presence of viable mould propagules in indoor air in relation to damp and outdoor air. Allergy (Copenhagen) 47(2 part 1):83-91.

Jenny Su H, Rotnitzky A, Burge HA, Spengler JD. 1992. Examination of fungi in domestic interiors by using factor analysis: correlations and associations with home factors. Appl Environ Microbiology. 58:181-6.

Pasanen, A.L., Heinonen-Tanski, H., Kalliokoski, P., Jantunen, M.J., 1992a. Fungal micro-colonies on surface an explanation for the base level fungal counts in indoor air. Atmospheric Environment. 117-120.

Li CS, Kuo YM. 1994. Characteristics of airborne microfungi in subtropical homes. The Science of the Total Environment. 155:267-71.

Rao CY, Burge HA. 1996. Review of quantitative standards and guidelines for fungi in indoor air. $\mathrm{J}$ of the Air and Waste Management Association. 46: 899-908.

Saoji, A.A. and Giri, S.K., 1997. Concentration of Aeroallergenic fungal spores in Intramural environments of Nagpur City - Hospital ward and Library. Proceeding 5th International Conference on Aerobiology, (Ed. S.N. Agashe), pp. 211-218. Oxford \& IPH Publishing Co. Ltd., New Delhi.

Dales R.E., Miller D., McMullen E. 1997. Indoor air quality and health: validity and determinants of reported home dampness and moulds. Int $\mathrm{J}$ Epidemiology. 26:120-5. 
Rosas I, Calderon C, Martinez L, Ulloa M, Lacey J, 1997. Indoor and outdoor airborne fungal propagule concentrations in Mexico City. Aerobiologia. 13:23-30.

Giri, S.K. and Saoji, A.A. 1998. Microbial pollution of air in intramural environments of Nagpur city. - Residential quarters and Food storage place. (M.S.). The Botanique. Commemoration Special Vol. XI. p. 27-32.

Garrett MH, Rayment PR, Hooper MA, Abramson MJ, Hooper BM. 1998. Indoor airborne fungal spores, house dampness and associations with environmental factors and respiratory health in children. Clin Exp Allergy. 28:459-67.

Darmage S, Bailey M, Raven J, Mitakakis T, Thien F, Forbes A, Guest D, Abramson M, Walters EH, 1999. Prevalence and residential determinants of fungi within homes in Melboune, Australia. Clin. and Exp. Allergy. 29:1481-9.

Singh, A.B. \& Singh A.D. 1999. Aspergillus spp. As an important occupational risk factor among susceptible individuals. Aerobiologia 15:233-240.

Ren P, Jankun TM, Belanger K, Bracken MB, Leaderer BP. 2001. The relation between fungal propagules in indoor air and home characteristics. Allergy.56:419-24.

Sessa R, Di Pietro M, Schiavoni G, Santino I, Altieri A, Pinelli S, Del Piano M. 2002. Microbiological indoor air quality in healthy buildings. Microbiologica. 25:51-6.

Shelton B, Kirkland K, Flanders W, Morris G (2002). Profiles of Airborne Fungi in Buildings and Outdoor Environments in the United States Appl. Environ. Microbiol., 68: 1743-53.

Ronald E Gots; Nancy J. Layton and Suellen W. Pirages (2003). Indoor health: Background levels of fungi. American Industrial Hygiene Association Journal 64:427-438.

Sawane, A.M. and Saoji, A.A. 2004. A report on Penicillium in the intramural and extramural air of residential areas of Nagpur city (India). Aerobiologia. Vol. 20 (3):229-236.

Hedayati, M.T. Pasqualotto, A.C., Warn, P.A., Bowyer, P. and Denning, D.W. 2007. Aspergillus flavus: human pathogen, allergen and mycotoxins producer. Microbiology, 153, 1677-1692. 
Sharma, D., Dutta B.K., Singh, A.B. and Shome B.R. 2007. Aerobiological, biochemical and immunological studies on some of the dominant Aspergillus species of South Assam (India), Aerobiologia 23(3): 201-210.

Gniadek A and Macura AB 2007. Intensive care unit environment contamination with fungi. Advances in Medical Sciences. 52: 283-287.

R Codina, RW Fox, RF Lockey, P DeMarco, A Bagg1, 2008. Typical levels of Airborne fungal spores in houses without obvious moisture problems during a Rainy Season in Florida, USA. J Investig Allergol Clin Immunol Vol. 18(3): 156-162.

Giri, S.K. and Sawane, A.M. (2010) Airborne Culturable Fungi in Hospital Environments of Nagpur (Maharashtra). Indian Journal of Aerobiology, vol. 23 (2): 80-85.

http://www.medicinenet.com/allergy/article.htm

Ellis, M. B. Dematiaceous Hyphomycetes. Kew; Commonwealth Mycological Institute, pp. 608, 1971.

Raper, K.B. and Fennell, D.I., 1977. Aspergillus ustus group. - In: The genus Aspergillus. Repr. R.E. Krieger Publ. Co. pp. 543-557. - Malabar, FL.

Raper, K.B. and Thom, C., 1949. A Manual of Penicillia. The williams and Wilkins Co. Baltimore.

Nagamani, I. K. Kunwar and C. Manoharachary. 2006. Hand book of Soil Fungi. I. K. International Pvt. Ltd. 